\title{
Depósito de Cu-Zn Pojuca Corpo Quatro: IOCG ou VMS?
}

\author{
Marcelo SCHWARZ ${ }^{1} \&$ José C. FRANTZ²
}

${ }^{1}$ Programa de Pós-graduação em Geociências, Instituto de Geociências, Universidade Federal do Rio Grande do Sul. Av. Bento Gonçalves, 9.500, CEP 91.501-970, Porto Alegre, RS, Brasil. E-mail: mrspirita@yahoo.com.

${ }^{2}$ Instituto de Geociências, Universidade Federal do Rio Grande do Sul. Av. Bento Gonçalves,9.500, CEP 91.501-970, Porto Alegre, RS, Brasil.E-mail: jose.frantz@ufrgs.br.

Recebido em 12/2011. Aceito para publicação em 12/2012.

Versão online publicada em 06/09/2013 (www.pesquisasemgeociencias.ufrgs.br)

\begin{abstract}
Resumo - Este trabalho trata do depósito de Cu-Zn designado como Pojuca Corpo Quatro, localizado na Província Mineral de Carajás, e procura estabelecer parâmetros para definir seu modelo metalogenético. 0 Depósito Pojuca Corpo Quatro está hospedado em rochas metavulcanossedimentares do Grupo Igarapé Pojuca, correlacionáveis às rochas do Grupo Grão Pará, de idade arqueana. A história metalogenética do depósito é complexa. Duas formas diferentes de ocorrência caracterizam os minerais de minério do depósito: uma mineralização stratabound, coerente com o bandamento das rochas hospedeiras e considerada primária, e um minério em brechas, vênulas e disseminado, aqui descrito como minério remobilizado ou secundário. As características das diferentes tipologias de minério sugerem duas fases de mineralização: mineralização primária, stratabound, cuja paragênese é constituída de calcopirita, pirrotita e esfalerita, considerada neste trabalho como sendo do tipo VMS, e a mineralização secundária ou remobilizada, de paragênese formada por pirrotita, calcopirita e molibdenita, descrita como sendo produto de eventos hidrotermais posteriores do tipo IOCG.
\end{abstract}

Palavras-Chave: IOCG, VMS, Pojuca Corpo Quatro, Cobre, Zinco, Carajás.

Abstract- Cu-Zn Pojuca Corpo Quatro Deposit: IOCG or VMS?. This paper deals about the Pojuca Corpo Quatro Cu-Zn deposit, located in Carajas Mineral Province, in order to establish parameters to define its metallogenic model. The Pojuca Corpo Quatro Deposit is hosted in Igarapé Pojuca Group metavolcanossedimentary rocks, which correlates to Grão Pará Group rocks of Archean age. The metallogenic history of this deposit is complex. Two different types of ore occurrence characterize the deposit, a stratabound mineralization, consistent with the host rock banding and considered primary, and another occurring in breccias, veinlets and disseminated, as described here as a remobilized or a secondary ore. The characteristics of these different types of ore suggest two phases of mineralization, the mineralization is stratabound or primary ore, with paragenesis composed of chalcopyrite, pyrrhotite and sphalerite, is considered here as being VMS type, and remobilized or secondary ore, formed by pyrrhotite, chalcopyrite and molybdenite, described as the product of IOCG ype subsequent hydrothermal events.

Key words: IOCG, VMS, Pojuca Corpo Quatro, Copper, Zinc, Carajás.

\section{Introdução}

O Depósito Pojuca Corpo Quatro teve suas reservas estimadas em 58 milhões de toneladas de minério, com teor médio de $0,87 \%$ de $\mathrm{Cu}$ e $0,90 \%$ de $\mathrm{Zn}$, com quantidades expressivas de $\mathrm{Au}, \mathrm{Ag}$ e $\mathrm{Cd}$. $\mathrm{O}$ depósito dista cerca de $35 \mathrm{~km}$ do Núcleo Urbano da Vale S.A., inserido na Floresta Nacional de Carajás, na porção norte da Província Mineral de Carajás, município de Parauapebas, sudeste do Estado do Pará, Brasil.

Este trabalho tem por objetivo a caracterização dos processos metalogenéticos do Depósito Pojuca Corpo Quatro, assim como o seu posicionamento no tempo geológico.

Para atingir os objetivos propostos, foram utiliza- dos dados coletados e gerados pela empresa Vale S.A., que realizou pesquisa na área desde a década de 70 , totalizando 15.163,46 m de sondagem distribuídos em 54 furos. Para o atual estudo, serão considerados os dados da seção -300E (furos F24, F31, F38 e F56). Os furos foram feitos utilizando sondas rotativas diamantadas, testemunhando com diâmetro HQ (96,40 mm) na cobertura intemperizada, geralmente até $100 \mathrm{~m}$, e NQ $(76,20 \mathrm{~mm})$ em rocha fresca.

O conhecimento geológico regional da Província Mineral de Carajás iniciou-se nas décadas de 20 e 30 por pesquisadores do Serviço Geológico e Mineralógico Brasileiro. Em meados da década de 50, o conhecimento da região foi impulsionado principalmente pelo levantamento aerofotogramétrico do sudeste do Pará 
sob contrato do Departamento Nacional de Produção Mineral e, a partir dos anos 60, as litologias foram agrupadas em unidades estratigráficas com base nos trabalhos de Barbosa et al. (1966), Ramos (1967) e Almeida et al. (1968) (in Araújo \& Maia, 1991).

Na década de 70, a Vale, já detentora das jazidas de ferro e manganês, desenvolveu trabalhos sistemáticos de pesquisas por meio de suas subsidiárias, mais particularmente a DOCEGEO. Atualmente, várias empresas de diferentes portes desenvolvem trabalhos de exploração mineral na província, prospectando $\mathrm{Fe}, \mathrm{Mn}, \mathrm{Cu}$, $\mathrm{Au}, \mathrm{Ni}, \mathrm{Pt}$ e Pd.

\section{Geologia Regional}

A Província Mineral de Carajás, onde está situado o Depósito Pojuca Corpo Quatro (Fig. 1), é limitada a leste pelos rios Araguaia-Tocantins, a oeste pelo rio Xingu, a norte pela Serra do Bacajá e a sul pela Serra dos Gradaús (Hirata et al., 1982). Baseado no contexto geotectônico, a Província de Carajás está localizada no Escudo do Brasil Central e inserida na porção sudeste da Província Amazônia Central, limitada pela Província Transamazônica ou Maroni-Itacaiúnas (Tassinari \& Macambira, 1999) a norte e pela Faixa Araguaia a leste, conforme mostra a figura 2 .

A litoestratigrafia proposta para a Província Mineral de Carajás é consequência de um conjunto de trabalhos realizados na região a partir da década de 60 . Foram definidas diversas unidades pré-cambrianas e agrupadas, por suas características, em embasamento cristalino arqueano subdividido em complexos Xingu e Pium e Suíte Plaquê, esta última constituída por granitóides arqueanos de associação TTG e sequências metavulcanossedimentares do tipo greenstone belt. Também, foram distinguidas sequências metassedi- mentares e metavulcanossedimentares arqueanas e paleoproterozóicas, as quais constituem o Supergrupo Itacaiúnas. Granitóides anorogênicos de idade paleo a mesoproterozóicas representam intrusões que cortam todas as unidades do Supergrupo Itacaiúnas, bem como as rochas da Formação Águas Claras. As unidades de cobertura fanerozóica são correlacionáveis ao Grupo Serra Grande.

Do ponto de vista metalogenético, essa província mineral constitui uma das mais bem estudadas regiões do Cráton Amazônico, englobando importantes depósitos de $\mathrm{Fe}, \mathrm{Cu}, \mathrm{Ni}, \mathrm{Au}$ e $\mathrm{Mn}$.

A Província Mineral de Carajás tem inúmeras propostas de colunas estratigráficas devido ao constante aporte de novos dados [(Lindenmayer (1990), Araújo \& Maia (1991), Costa et al. (1993), Pinheiro \& Holdsworth (1995) e Barros (1995 e 1997)]. As principais tentativas de sistematização do conhecimento regional utilizadas pelas empresas em atuação na região são as de Hirata et al. (1982), e a proposta por geólogos da Vale (DOCEGEO, 1988 - Relatório Interno), conforme figura 3.Trabalhos mais recentes têm dado ênfase à evolução tectonoestratigráfica, petrogênese, metalogênese e, principalmente, a geocronologia das rochas da Província Mineral de Carajás como, por exemplo, os de Pinheiro \& Holdsworth (2000), Althoff et al. (2000), Pidgeon et al. (2000), Barros et al. (2001), Barbosa et al. (2001), Macambira et al. (2001), Leite (2001) e Villas \& Galarza (2001), dentre outros.

\section{Estratigrafia e evolução tectonoestratigráfica}

As principais unidades litoestratigráficas ocorrentes na região da área em estudo e arredores estão incluídas dentro do Supergrupo Itacaiúnas, sintetizadas adiante, e que podem ser observadas no mapa geológi-

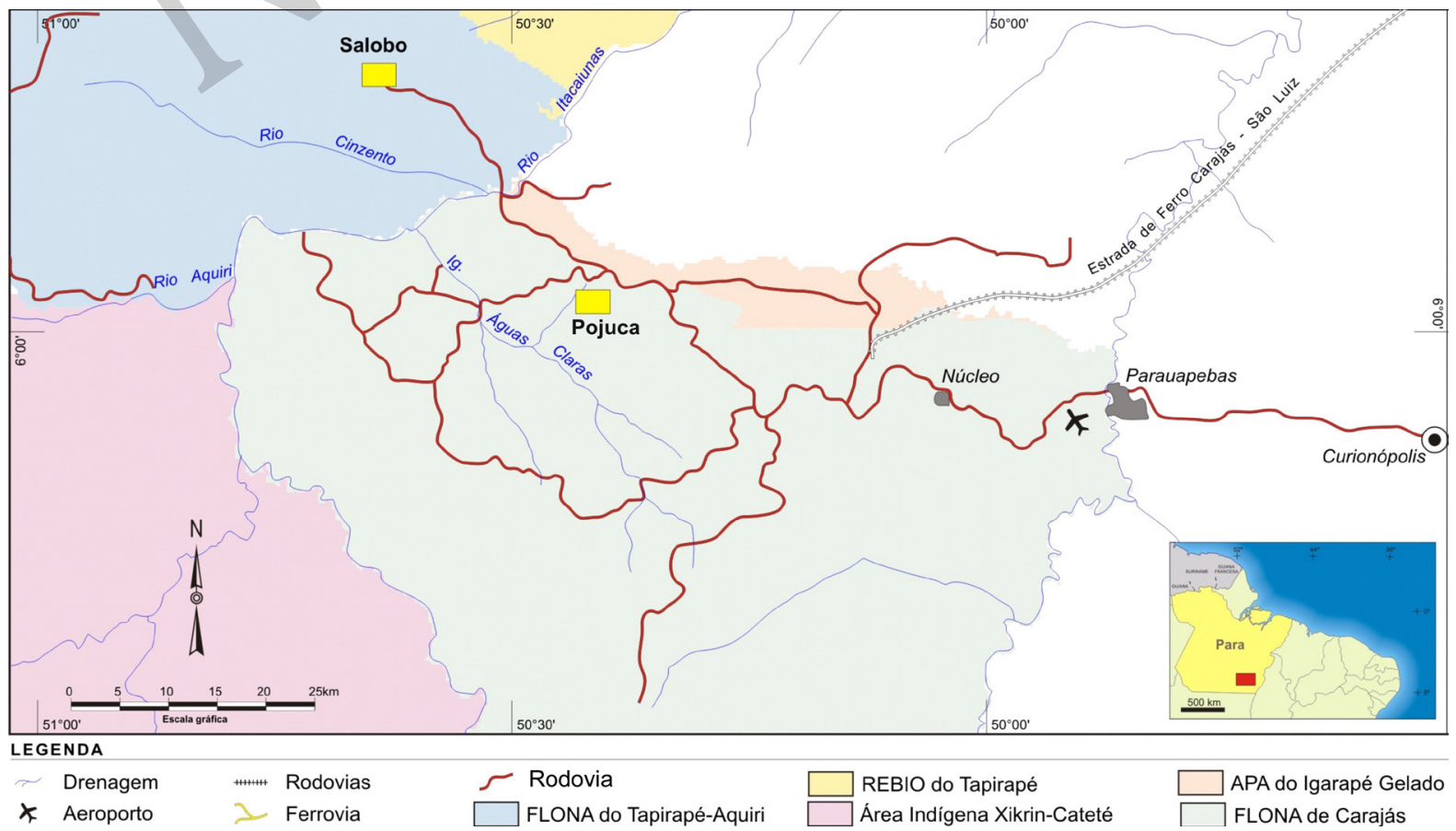

Figura 1. Localização e vias de acessos do Depósito Pojuca Corpo Quatro, Província Mineral de Carajás, Pará. 


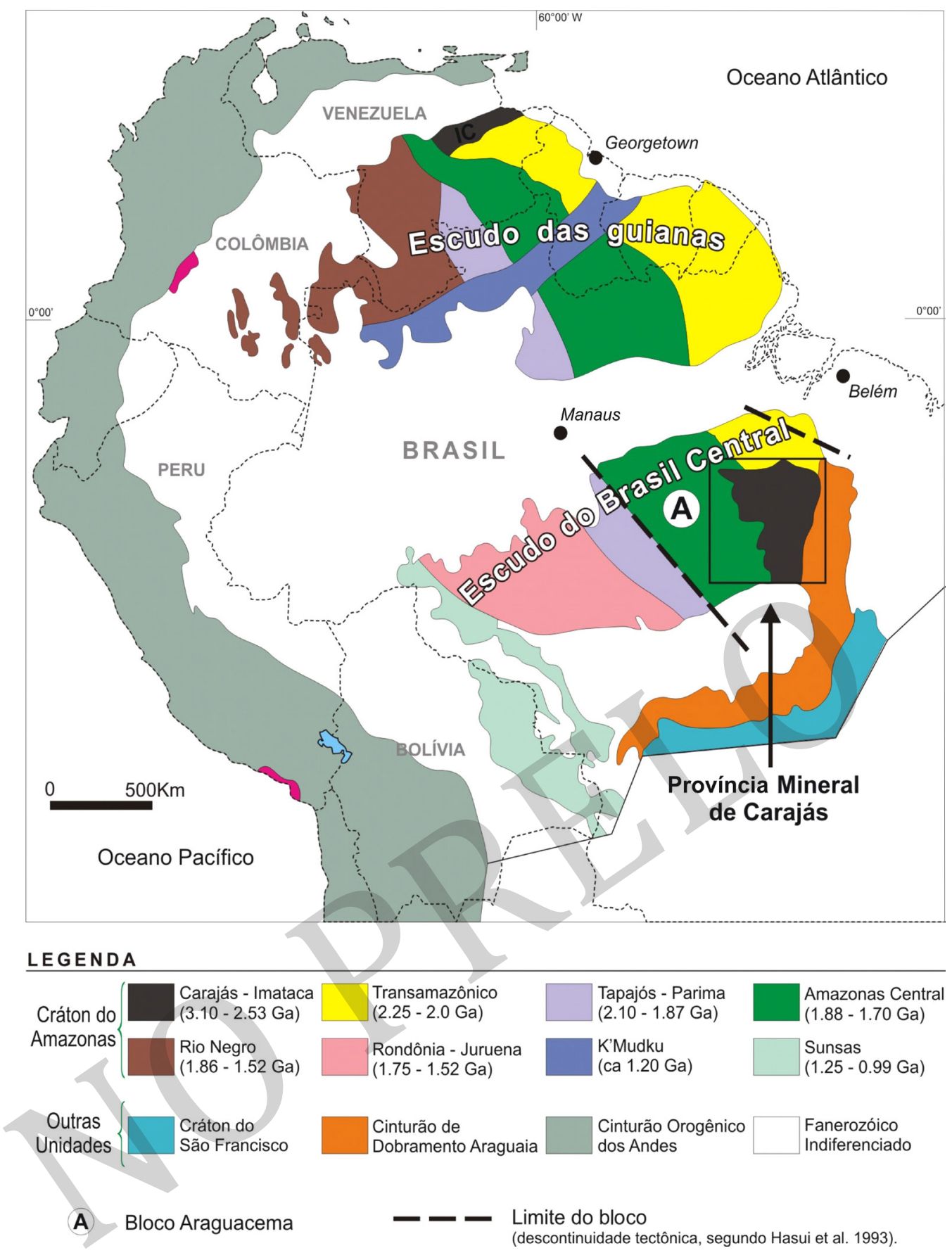

Figura 2. Compartimentação tectônica do Cráton Amazônico.

co regional apresentado na figura 4.

O Supergrupo Itacaiúnas está em contato discordante com os granitóides, gnaisses e migmatitos do Complexo Xingu. Este supergrupo engloba todas as sequências de rochas supracrustais da Província Mineral de Carajás, que diferem em grau metamórfico e composição das sequências de greenstone belts do Supergrupo Andorinhas. Desse modo, foram agrupados, da base para o topo, os grupos Igarapé Salobo, Igarapé Pojuca, Grão-Pará, Igarapé Bahia e Buritirama.

\subsection{Grupo Igarapé Salobo}

O grupo compreende uma faixa deformada, de direção WNW, composta por anfibolitos, xistos, formações ferríferas, metagrauvacas depositados entre 2732 e $2742 \mathrm{Ma}$ (U/Pb, Machado et al., 1991). Estas rochas, descritas no depósito de $\mathrm{Cu}-\mathrm{Au}$ do Salobo inicialmente como metamórficas (Lindenmayer, 1990), foram reinterpretadas como provenientes de processos de alteração hidrotermal que acompanharam a deposição dos sulfetos de cobre (Lindenmayer \& Teixeira, 1999). Rochas vulcânicas andesíticas são interpretadas como provenientes de magmas cálcio-alcalinos, com geoquímica análoga a de magmas de arcos magmáticos ( $\mathrm{ENd}$ $(T)=-1,8$ ) (Lindenmayer et al., 2001).

\subsection{Grupo Igarapé Pojuca}

O Grupo Igarapé Pojuca, objeto do presente estudo, tem ampla distribuição nas bordas do "Sinclinório Carajás", abrangendo sequências de rochas metavulca- 


\begin{tabular}{|c|c|c|c|c|}
\hline \multirow[b]{2}{*}{ Eras } & \multirow[b]{2}{*}{ Ga } & \multicolumn{3}{|c|}{ Cinturão de Cisalhamento Itacaiúnas } \\
\hline & & $\begin{array}{l}\text { Complexos ou } \\
\text { Supergrupos }\end{array}$ & $\begin{array}{l}\text { Grupos ou } \\
\text { Formações }\end{array}$ & Rochas Intrusivas \\
\hline \multirow[t]{6}{*}{ Proterozóica } & 1.9 & & & $\begin{array}{l}\text { granitos anorogênicos (S. dos Carajás } \\
\text { Cigano, Pojuca, Antônio Vicente) } \\
\text { Gabro Santa Inês }\end{array}$ \\
\hline & 2.5 & & & Old Salobo, Itacaiúnas e Planalto \\
\hline & 2.6 & & & $\begin{array}{l}\text { sills e diques básicos, Suíte Plaquê e } \\
\text { intrusão máfica }\end{array}$ \\
\hline & \multirow{8}{*}{2.8} & \multirow{8}{*}{$\begin{array}{l}\text { Supergrupo } \\
\text { Itacaiúnas }\end{array}$} & $\begin{array}{l}\text { Fm. Águas } \\
\text { Claras }\end{array}$ & Borrachudo \\
\hline & & & Gr. Buritirama & \\
\hline & & & $\begin{array}{l}\text { Gr. Igarapé } \\
\text { Bahia }\end{array}$ & \\
\hline \multirow[t]{6}{*}{ Arqueana } & & & Gr. Grão Pará & \\
\hline & & & Gr. Ig. Pojuca & \\
\hline & & & Gr. Ig. Salobo & \\
\hline & & & & $\begin{array}{l}\text { Intrusão } \\
\text { Ultramáfica Luanga }\end{array}$ \\
\hline & & & & Granito Estrela \\
\hline & 3.1 & $\begin{array}{r}\text { Complexo Xingu } \\
\text { e Complexo Pium }\end{array}$ & & \\
\hline
\end{tabular}

Figura 3. Coluna estratigráfica da Província Mineral de Carajás, modificada de DOCEGEO (1988), Fonte: Villas \& Santos (2001).

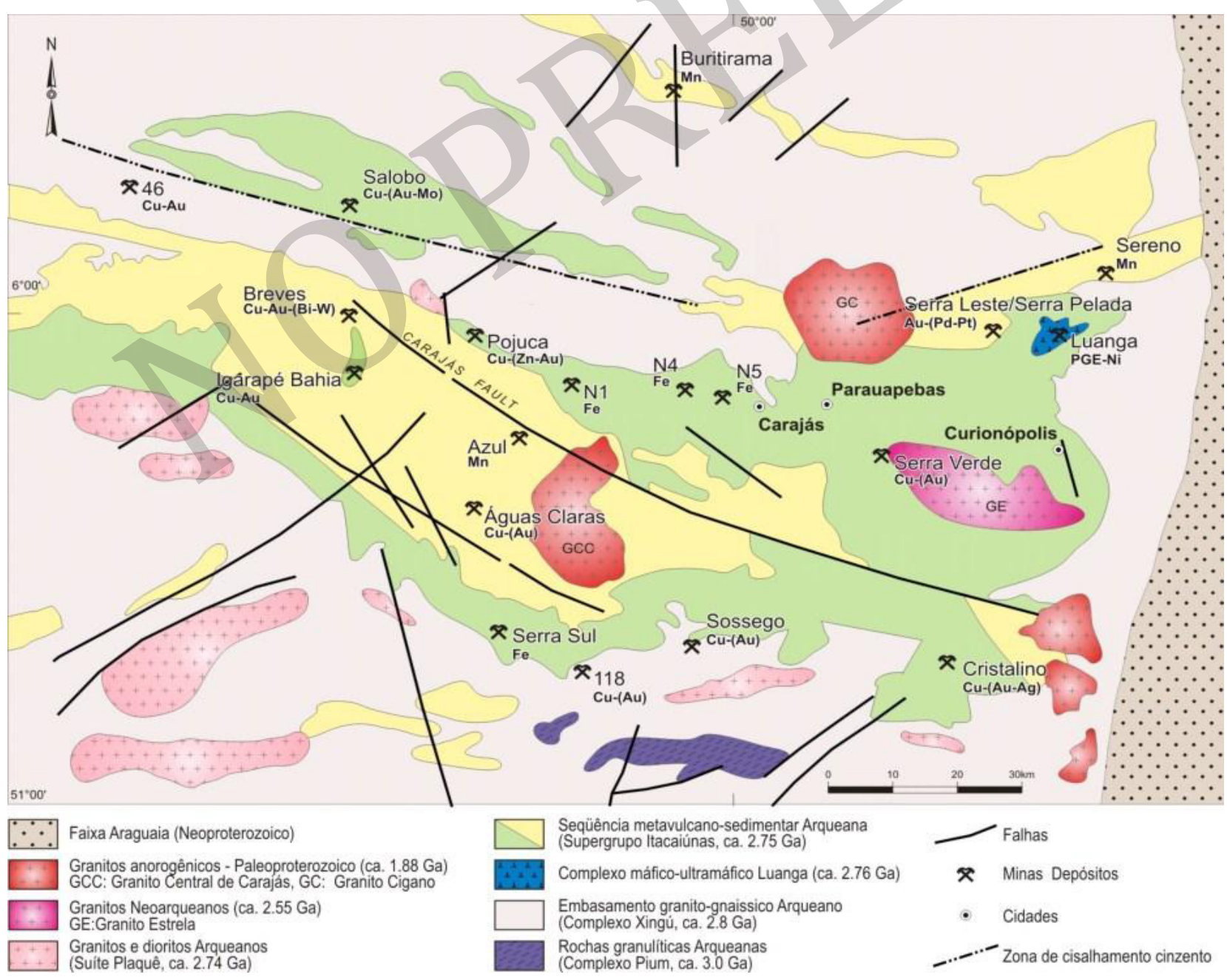

Figura 4. Mapa geológico da Província Mineral de Carajás, mostrando a localização do depósito Furnas Cu-Au e os principais depósitos de Fe, Mn e Cu-Au, simplificado de DOCEGEO (1988), Araújo Maia (1991) e Barros \& Barby (1998). 
nossedimentares, de fácies xistos verdes a anfibolito, orientadas segundo direção geral WNW-ESE com mergulhos variando de $50^{\circ} \mathrm{NE}$ a $60^{\circ} \mathrm{SW}$. A seção-tipo foi definida na área que abriga os depósitos de $\mathrm{Cu}-\mathrm{Zn}$ e $\mathrm{Cu}$ -Au-Mo e descrita por DOCEGEO (1988) como rochas metavulcânicas básicas a intermediárias (muitas vezes alteradas hidrotermalmente para cordierita-antofilita, anfibólios, sílica, biotita), anfibolitos, gnaisses, cherts, formações ferríferas bandadas (BIFs) e xistos de composições diversas. Foi caracterizada a Formação Corpo Quatro, que abriga depósito homônimo e caracteriza-se por dois grupamentos litológicos principais: rochas bandadas e rochas com fragmentos. As rochas bandadas correspondem a sedimentos químicos com sulfetos (pirrotita, calcopirita, esfalerita), níveis descontínuos de chert e/ou formação ferrífera bandada fácies óxido, bem como vários níveis de sulfeto maciço. As rochas com fragmentos apresentam disseminações de pirrotita, calcopirita e, eventualmente, esfalerita. 0 metamorfismo das rochas do Igarapé Pojuca foi datado por Machado et al. (1991) como ocorrido em 2740 - 2730 Ma pelo método $\mathrm{U}-\mathrm{Pb}$ em zircões.

As mineralizações de $\mathrm{Cu}-\mathrm{Zn}$ são consideradas singenéticas e relacionadas à fácies sulfeto dos BIFs, enquanto a mineralização de $\mathrm{Cu}-\mathrm{Au}$-Mo adjacente, conhecida como Depósito Gameleira, está provavelmente relacionada a processos de remobilização tardia em stockwork.

\subsection{Grupo Grão-Pará}

O Grupo Grão Pará (Beisiegel et al., 1973) é formado por três unidades, da base para o topo: Formação Parauapebas (DOCEGEO, 1988), Formação Carajás (Beisiegel et al., 1973) e a Sequência Paleovulcânica Superior (Beisiegel et al., 1973; DOCEGEO, 1988), esta última correspondendo a Upper Metasedimentary Sequence de Gibbs et al. (1986).

A Formação Parauapebas é constituída por basaltos, basaltos andesíticos, shoshonitos e riolitos, cortados por corpos quartzo-dioríticos (Gibbs et al., 1986; Teixeira, 1994), metamorfisados na fácies xistos verdes e pouco deformados. No topo da Formação Parauapebas dominam rochas vulcânicas félsicas, traquiandesitos e riolitos, cuja efusão deu-se entre $2743 \pm 11 \mathrm{Ma}$ (U-Pb, zircão, Trendall et al., 1998) e $2759 \pm 2$ Ma (U/ $\mathrm{Pb}$, Machado et al., 1991). Estes dados indicam sincronicidade entre a Formação Parauapebas e a deposição do Grupo Salobo-Pojuca.

A Formação Carajás abriga as formações ferríferas bandadas fácies óxido e carbonato, que representam o protominério dos depósitos de ferro supergênicos. Sua idade mínima é determinada por um sill máfico datado de $2740 \pm 8$ Ma. (U-Pb, zircão, Trendall et al. ,1998).

A Sequência Paleovulcânica Superior compreende rochas vulcânicas, metagrauvacas, siltitos tufáceos, filitos, arenitos, com derrames basálticos, tufos e arenitos tufáceos (Gibbs et al. ,1986).

\subsection{Grupo Igarapé Bahia}

O Grupo Igarapé Bahia, de ocorrência restrita à área da mina de ouro do mesmo nome, é considerado por DOCEGEO (1988) como sobreposto às rochas do Grupo Grão Pará. Compreende uma sequência de rochas vulcanossedimentares de baixo grau metamórfico (hidrotermalismo), contendo mineralização primária de $\mathrm{Cu}$, associado a $\mathrm{Au}$, Mo e Ag, e mineralização secundária de $\mathrm{Au}$ em gossans. As rochas deste grupo são metassedimentares, pelitos e ritmitos, e metavulcanoclásticas félsicas a máficas intercaladas, com intrusivas máficas (DOCEGEO, 1988) que afloram em uma janela estrutural situada na porção centro-oeste da região de Carajás. Nas zonas de minério, há um domínio de brechas hidrotermais bem caracterizadas e preferencialmente hospedadas na interface entre rochas vulcânicas e rochas piroclásticas/ritmitos do pacote.

\subsection{Grupo Buritirama}

O grupo é representado por um pacote de rochas metassedimentares clásticas e químicas de direção N55W, que aflora na serra homônima, na porção norte da Província Mineral de Carajás. 0 pacote corresponde, da base para o topo, a quartzitos bandados, quartzitos micáceos e xistos variados. Contém reservas de $\mathrm{Mn}$, as quais vêm sendo explotadas desde 1979 e foram avaliadas, nessa época, em 17,730 milhões de toneladas com teor médio de $47 \%$ de $\mathrm{MnO}_{2}$.

\subsection{Formação Águas Claras}

Essa formação foi sugerida por Araújo et al. (1988) e descrita por Nogueira (1995), anteriormente correlacionada por DOCEGEO (1988) ao Grupo Rio Fresco. Ela compreende rochas sedimentares marinhas a fluviais, cortadas por sills e diques de rochas máficas (Soares et al., 1994) e está repousando de forma discordante sobre as rochas do Supergrupo Itacaiúnas.

\subsection{Modelo tectonoestratigráfico}

Os três principais modelos tectonoestratigráficos propostos para a Provícia Mineral de Carajás são os de Araújo \& Maia (1991), Costa et al. (1995) e de Pinheiro (1997), sendo o último adotado no presente trabalho.

Pinheiro (1997) sugere que a evolução tectônica de Carajás teve início com o estabelecimento de uma zona de cisalhamento dúctil arqueana, de direção E-W (Zona de Cisalhamento Itacaiúnas), responsável pelo desenvolvimento de uma fábrica milonítica de alta temperatura gerada por transpressão sinistral nas rochas do embasamento, seguida pela instalação sobre o embasamento representado pelas rochas do Grupo Igarapé Pojuca. As rochas do grupo foram deformadas por transpressão e, sobre estas, os litotipos do Grupo Grão Pará $(2,7 \mathrm{Ga})$ foram posicionadas. De forma discordan- 
te, sobre o Grupo Grão Pará, foram depositados os sedimentos da Formação Águas Claras. Posteriormente, um evento transtensional dextral gerou uma geometria sigmoidal alongada, com trend E-W, fortemente controlada pela geometria das zonas de cisalhamento pretéritas. A Falha Carajás marca o limite de deslocamento dextral transtensivo da Estrutura de Carajás, a qual foi invadida por um enxame de diques e sills máficos por volta de 2,6 Ga. Um episódio de transpressão sinistral entre 2,6 Ga e 2,0 Ga reativou a Falha Carajás, deformando as rochas situadas no interior da estrutura e, no contexto do Sistema Transcorrente Cinzento, dando origem a estruturas sidewall ripout. Um último episódio deformacional, controlado por uma extensão E-W a NE-SW ocorrida durante o Proterozóico Inferior e o início do Mesoproterozóico, no Cráton Amazônico, deu origem a fraturas e falhas regionais de direção N-S e permitiu a intrusão de corpos graníticos (granitos Carajás, Cigano, dentre outros) e, possivelmente, novas injeções de diques máficos.

\section{Geologia do Depósito}

A mineralização do Depósito Pojuca Corpo Quatro está associada a uma faixa estreita (variável de 1 a 3 $\mathrm{km}$ ) de rochas metavulcanossedimentares inseridas no Grupo Igarapé Pojuca (DOCEGEO, 1988) de direção geral NW situada entre rochas do Complexo Xingu a norte e rochas sedimentares da Formação Águas Claras a sul. O Granito Pojuca, anorogênico proterozóico, corta as sequências do depósito (Fig. 5).

O Bloco Pojuca corresponde à extremidade $\mathrm{W}$ do bloco norte individualizado pela Falha Carajás durante sua movimentação sinistral devido à convergência NE. Os lineamentos e falhamentos associados à falha principal são de orientação NW-SE. Outras direções de fraturamentos subordinadas são NE-SW, NS, EW, todos subverticais. A deformação nas rochas é heterogênea, ocorrendo faixas mais deformadas.

As rochas metavulcânicas presentes na área apresentam, no domínio do depósito, uma foliação de direção preferencial NW-SE, com mergulhos de $60-80^{\circ}$ para SW quando próximas ao contato com a Formação Águas Claras e mergulhos de $50-60^{\circ}$ para NE naquelas próximas ao limite norte, em contato com o Complexo Xingu. As rochas vulcânicas correspondem predominantemente a metabasaltos e metabasaltos andesíticos metamorfisados à fácies anfibolito com texturas granobásticas, xenoblásticas e subidioblásticas, e hidrotermalizadas (Fig. 6). 0 basalto de footwall encontra-se localmente hidrotermalizado, com paragênese formada por antofilita-cordierita-granada, hospedando ou não veios centimétricos e vênulas de calcopirita. Já o metabasalto do hangwall, considerado por alguns autores como um sill gabróico em função da sua granulometria grossa, é interpretado neste trabalho como parte da sequência vulcânica, não apresentando sinais de hidrotermalismo característico da base de sistemas vulcânicos, como esperado em sistemas VMS. Na porção sudeste do Depósito Pojuca Corpo Quatro, ocorrem metassedimentos de baixo grau compostos por arenitos, conglomerados e siltitos, que estão em contato tectônico com os metabasaltos do footwall.

A Formação Corpo Quatro, que hospeda as mineralizações de $\mathrm{Cu}-\mathrm{Zn}$, tem espessura média de $100 \mathrm{~m}$. Trata-se de uma unidade composta por sedimentos clasto-químicos divididos em dois grupos litológicos principais: rochas com fragmentos e rochas bandadas. As rochas com fragmentos, cuja mineralogia principal é representada por quartzo, almandina e biotita ou hornblenda, também podem ser hospedeiras de mineralização, por vezes apresentando disseminações de calcopirita, pirrotita e esfalerita. 0 nome desta unidade provém da presença de agregados alongados de quartzo sub-arredondados a angulares, por vezes com aparência fragmental, clástica e interpretados como sendo de origem sedimentar, que representariam clastos intrabasinais (Winter, 1994).

\section{Mineralização}

A mineralização do Depósito Pojuca Corpo Quatro, sob o ponto de vista estrutural e composicional apresenta diferenças que permitem interpretar o depósito como originado a partir de duas situações geológicas e correspondendo a duas formas de distribuição da mineralização: a primeira bandada, stratabound, é interpretada como primária e, a segunda, presente em rochas brechadas, vênulas e disseminações, é interpretada como remobilizada ou secundária.

A mineralização primária ocorre, principalmente, nas rochas bandadas, com características de exalitos, formadas por níveis milimétricos a centimétricos de sedimentos químicos com anfibólio, quartzo, sulfetos de $\mathrm{Fe}, \mathrm{Cu}$ e $\mathrm{Zn}$, e magnetita, intercalados com níveis pelito-químicos com anfibólio, almandina, biotita, quartzo, magnetita e, subordinadamente, sulfetos. Níveis de chert e de formação ferrífera bandada ocorrem próximos à base da unidade rochas bandadas (Figs. 7 e 8).

A mineralização secundária ou remobilizada ocorre sobre as rochas com fragmentos, assim como sobre as rochas encaixantes metavulcanossedimentares. A forma de ocorrência desta fase mineralizante varia de disseminações a veios de quartzo ou carbonato, sendo correlacionada a eventos tardios, sejam estes novos aportes de fluido responsáveis pela entrada de mais carga metálica no sistema, e/ou pela simples remobilização de sulfetos já presentes nas rochas da região (Figs. 9, 10 e 11).

O somatório das espessuras médias dos corpos mineralizados do Depósito Pojuca Corpo Quatro chega a $70 \mathrm{~m}$ e possui extensão total de $2,6 \mathrm{~km}$. Os corpos mineralizados têm formas lenticulares e/ou tabulares concordantes com o bandamento das rochas hospedeiras, podendo ser irregulares e às vezes até mesmo anastomosados, com espessuras variando entre 5 e $35 \mathrm{~m}$. 


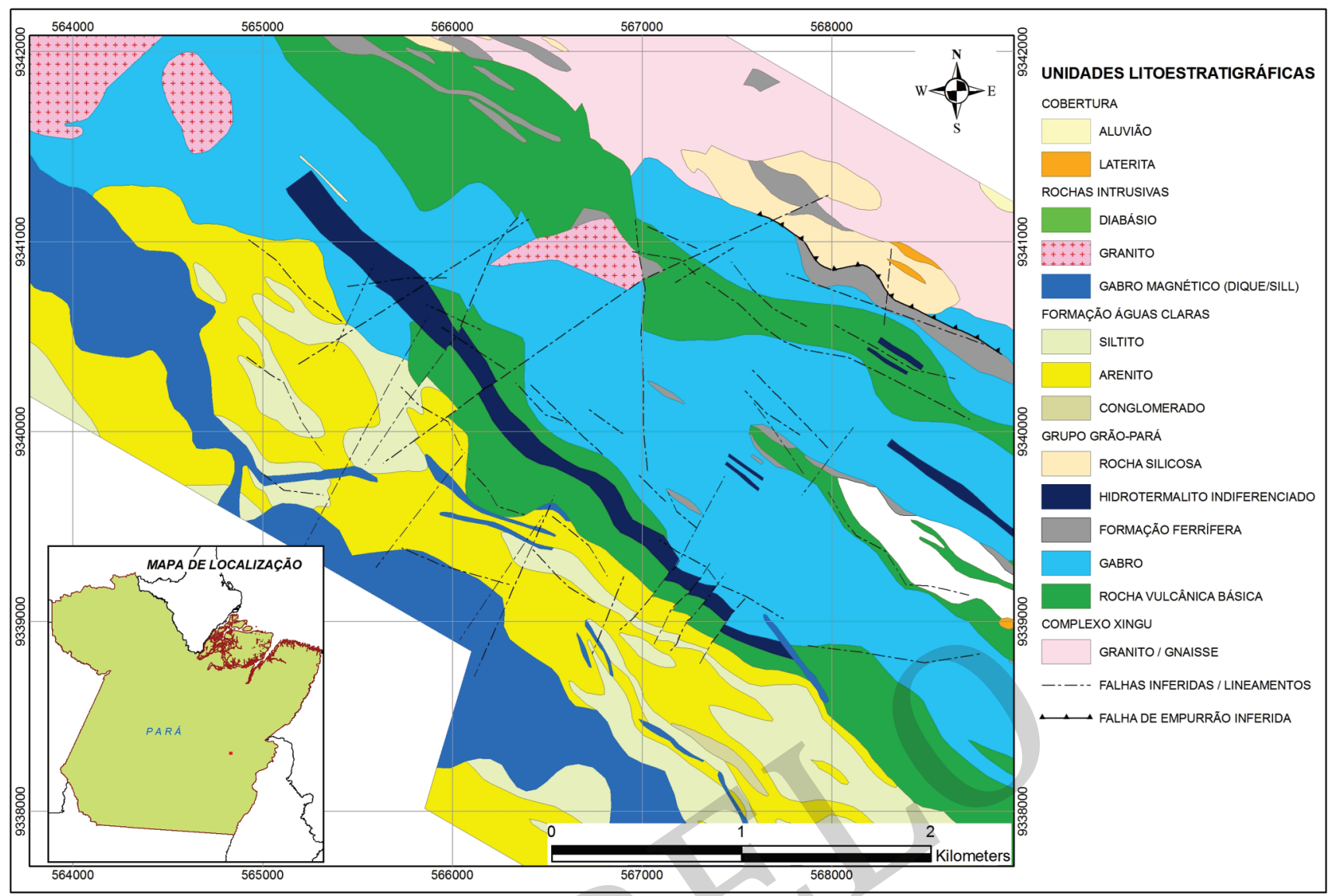

Figura 5. Mapa do Depósito Pojuca Corpo Quatro e adjacências.

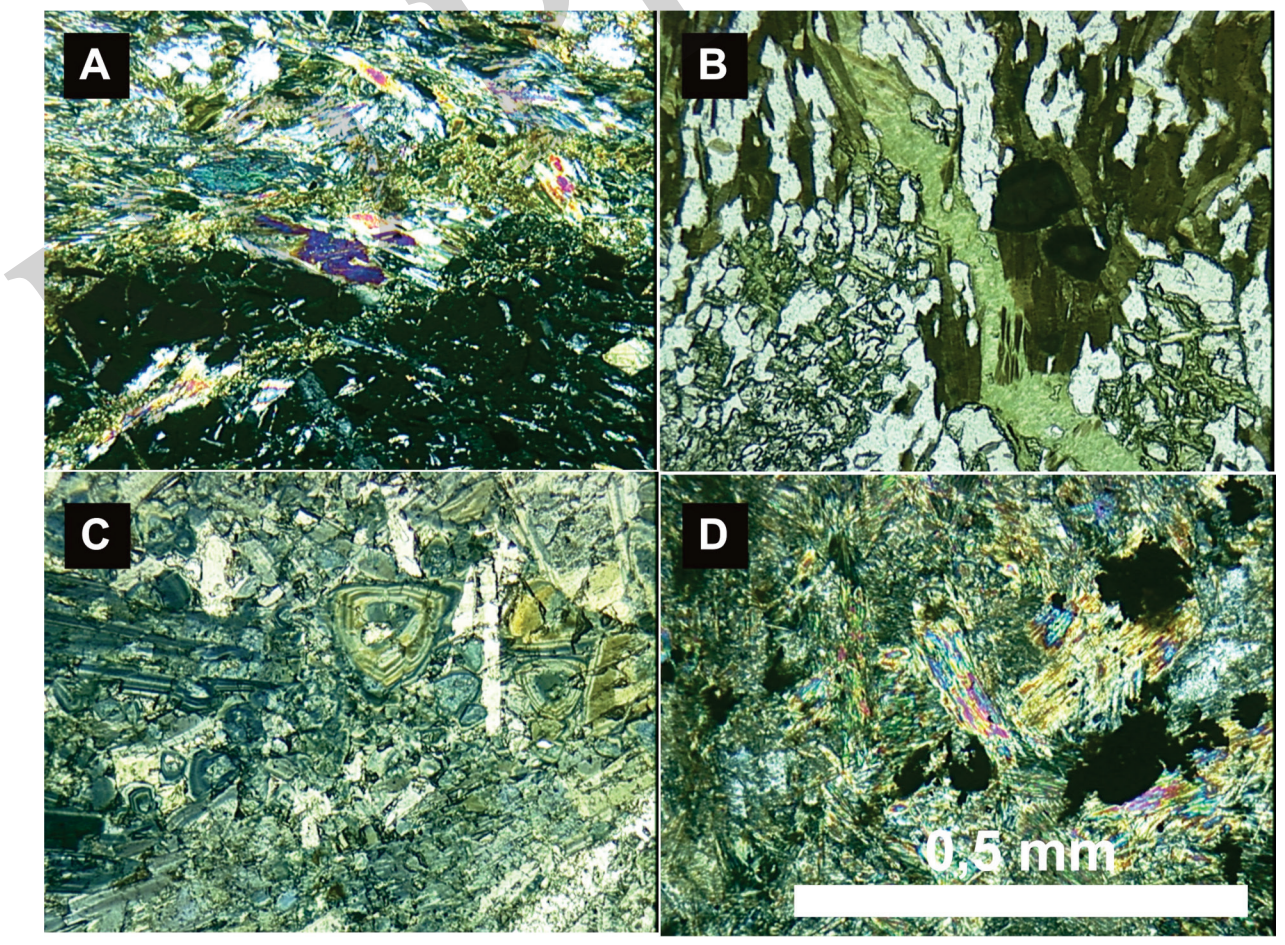

Figura 6. Fotomicrografias da rocha metavulcânica hidrotermalizada encaixante do minério: (A) luz transmitida, nicóis cruzados, mostrando biotita e clorita com xenoblastos de anfibólio, marcando a foliação, porfiroblastos de granada com inclusões de ilmenita, e plagioclásio hidrotermalizado; (B) luz transmitida, nicóis paralelos, mostrando cristais zonados de turmalina, biotita, agregados granoblásticos de quartzo e fraturas preenchidas por clorita; (C) luz transmitida, nicóis paralelos, mostrando turmalina zonada, xenoblastos de quartzo em fraturas e clorita orientada definindo a foliação principal; (D) rocha metavulcânica básica a intermediária, luz transmitida, nicóis cruzados, mostrando anfibólio primário, substituído por anfibólio acicular secundário e clorita, lamelas de biotita, xenoblastos de plagioclásio hidrotermalizado e ilmenita disseminada. 


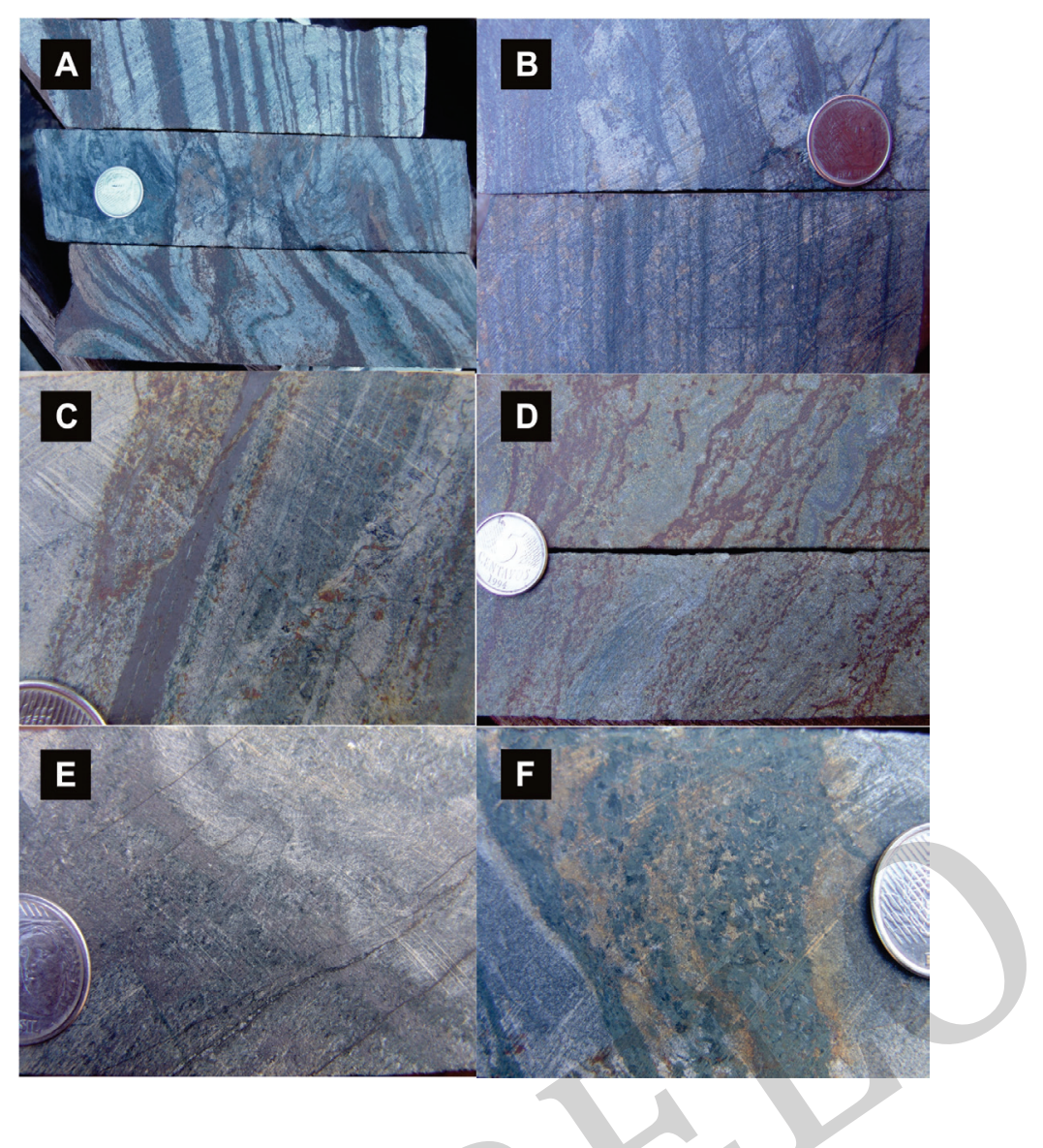

Figura 7. Feições macroscópicas do minério primário: (A) formação ferrífera bandada, hidrotermalizada, com magnetita, quartzo, anfibólio, biotita e calcopirita; (B) com granada; (C) intercalada com chert; (D) martitizada; (E e F) brechada com in fills tardios de anfibólio.

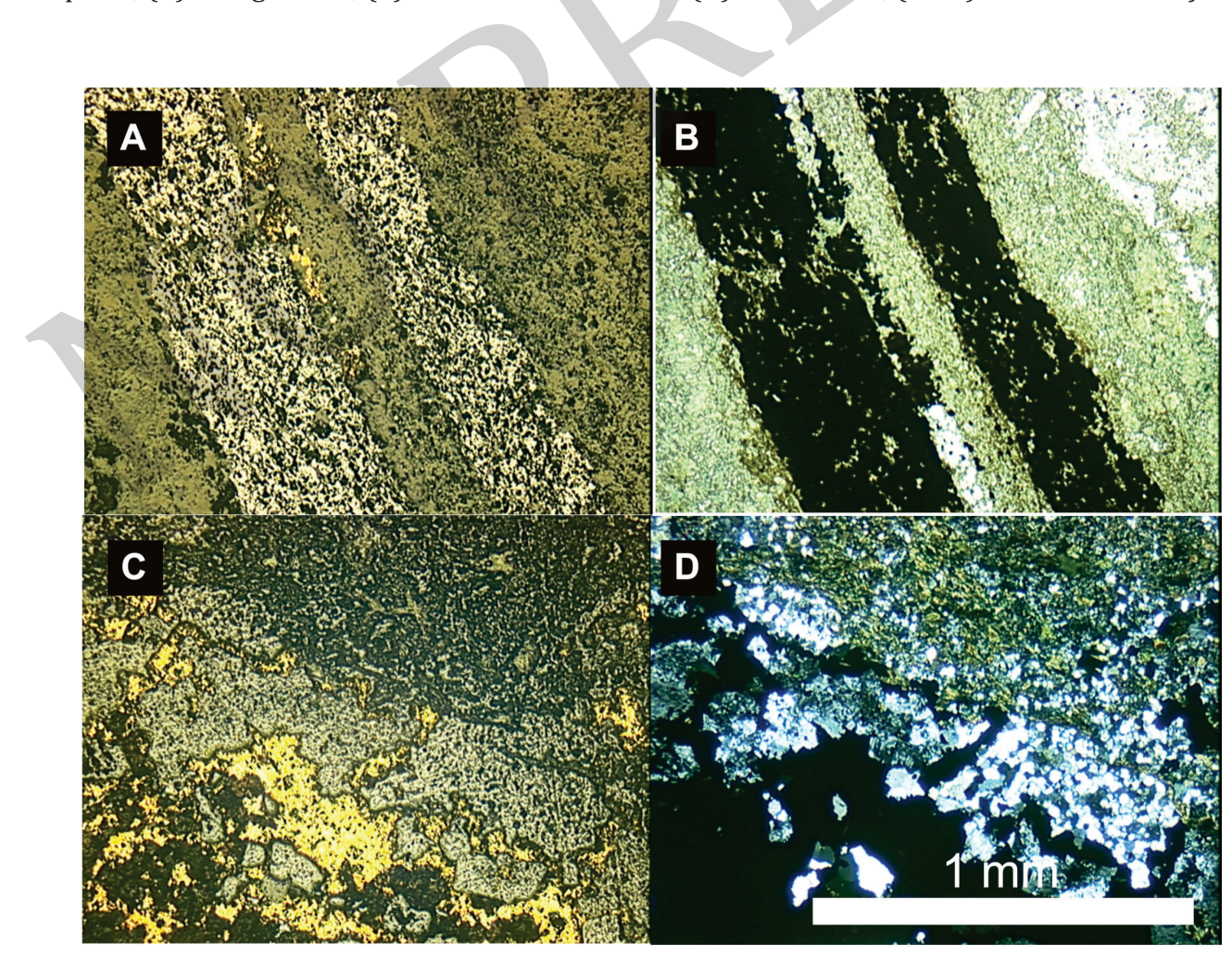

Figura 8. Seções delgadas de formações ferríferas bandadas fácies óxido/silicato: (A) na fácies óxido, luz refletida, ocorre magnetita, ilmenita, calcopirita e pirita como xenoblastos, e inclusões de ilmenita em magnetita; (B) bandas milimétricas da fácies silicato, com xenoblastos de quartzo e anfibólio com substituição parcial por biotita; (C) detalhe da rocha bandada na porção quartzosa, luz refletida, com massas anédricas de calcopirita associadas a pirrotita, pirita e esfalerita, com ouro muito fino incluso na pirita; (D) xenoblastos de plagioclásio e de anfibólio, com substituição por biotita e epidoto. 


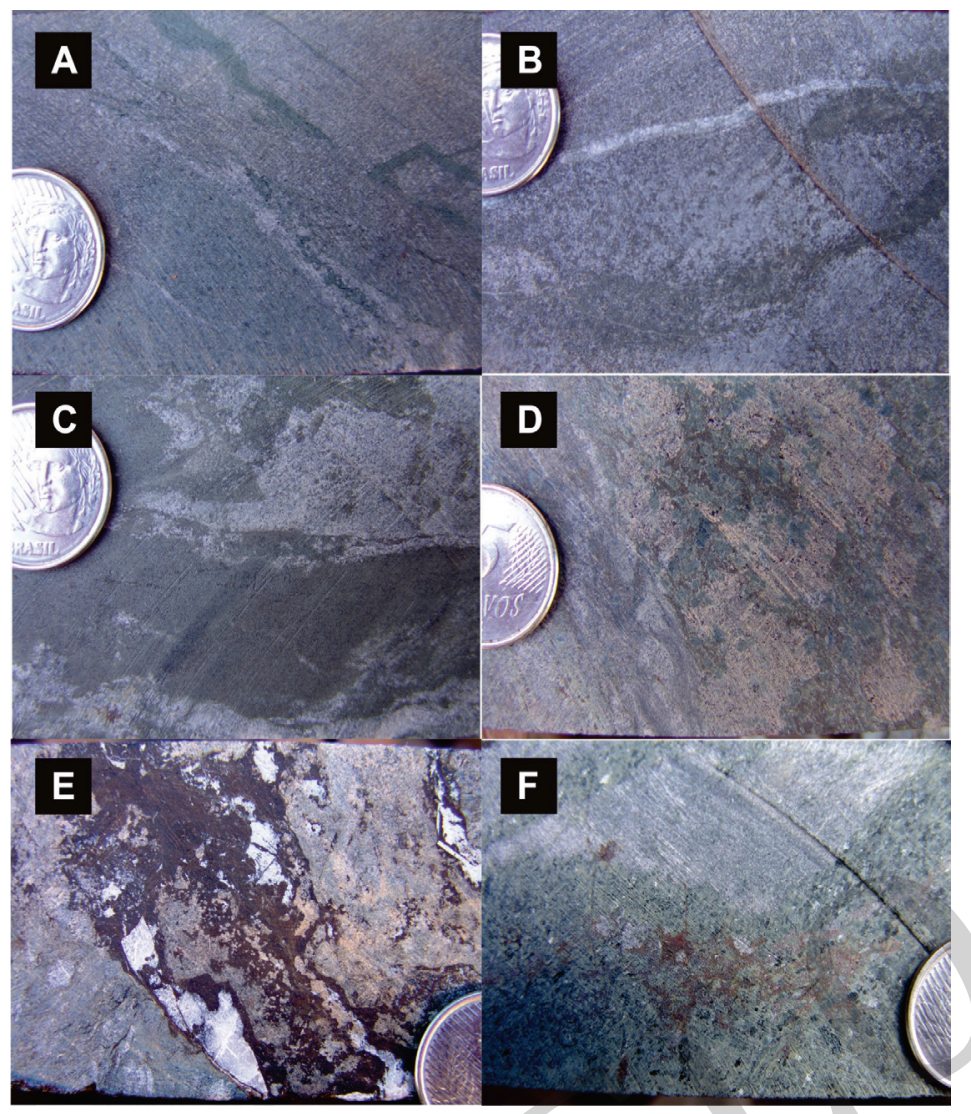

Figura 9. Feições macroscópicas das rochas encaixantes e do minério remobilizado: (A, B e C) em rocha vulcânica básica anfibolitizada, com veios tardios de clorita e quartzo; (D) rocha com fragmentos de anfibólio, granada e magnetita; (E) rocha com fragmentos de anfibólio, granada e biotita, com brechas tardias com carbonato e magnetita; (F) anfibolitização com grãos grossos e remobilização de sulfetos.

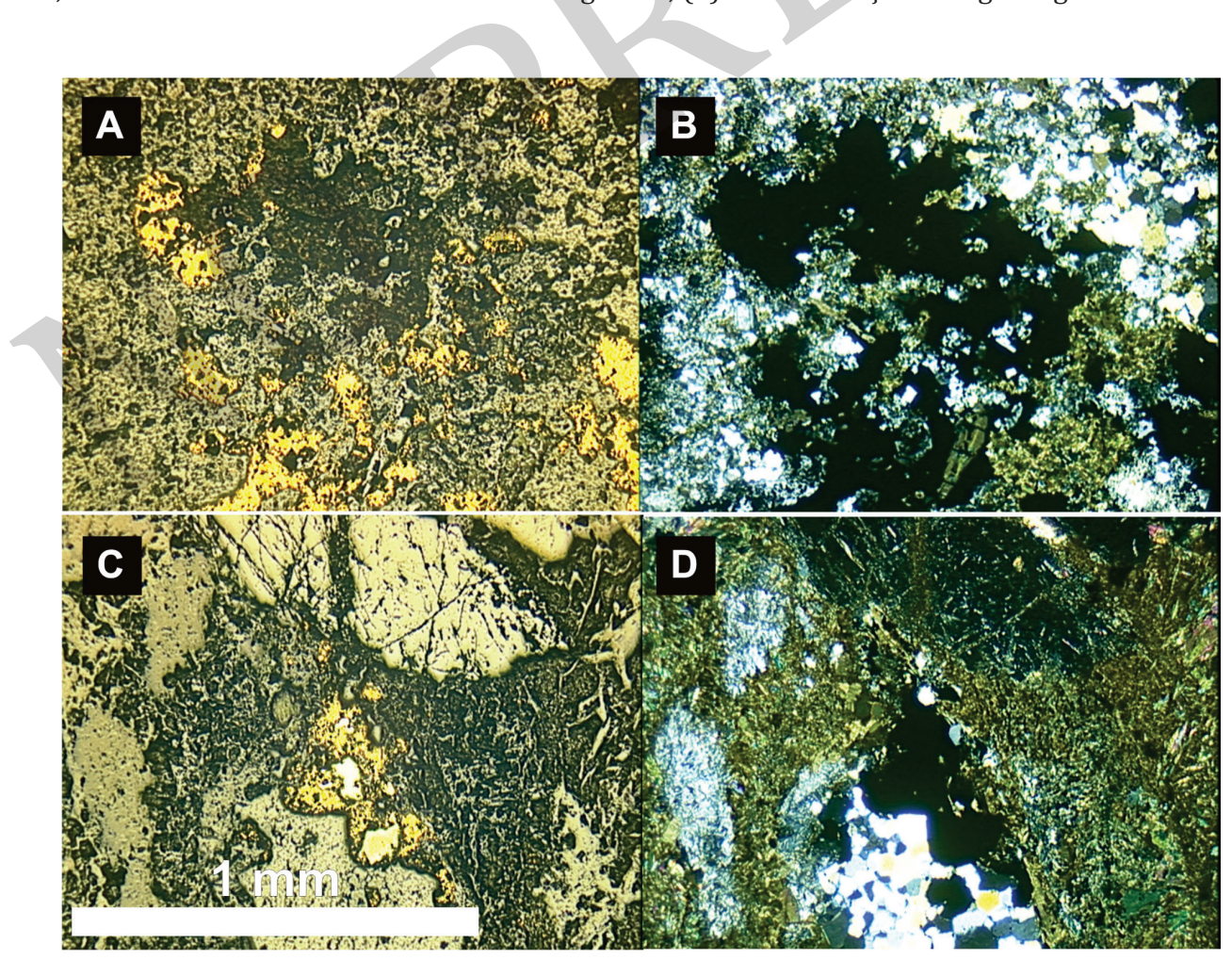

Figura 10. Fotomicrografias: (A) Vênula mineralizada a calcopirita, em massas anédricas, com xenoblastos de esfalerita; (B) rocha com agregados granoblásticos de quartzo, xenoblastos de plagioclásio alterados a epidoto com agregados de biotita; (C) pirita inclusa e corroída em massas anédricas de calcopirita; (D) rocha metavulcanossedimetar hidrotermalizada com porfiroblastos de granada, plagioclásio hidrotermalizado, anfibólio, biotita e agregados xenoblásticos de quartzo. 


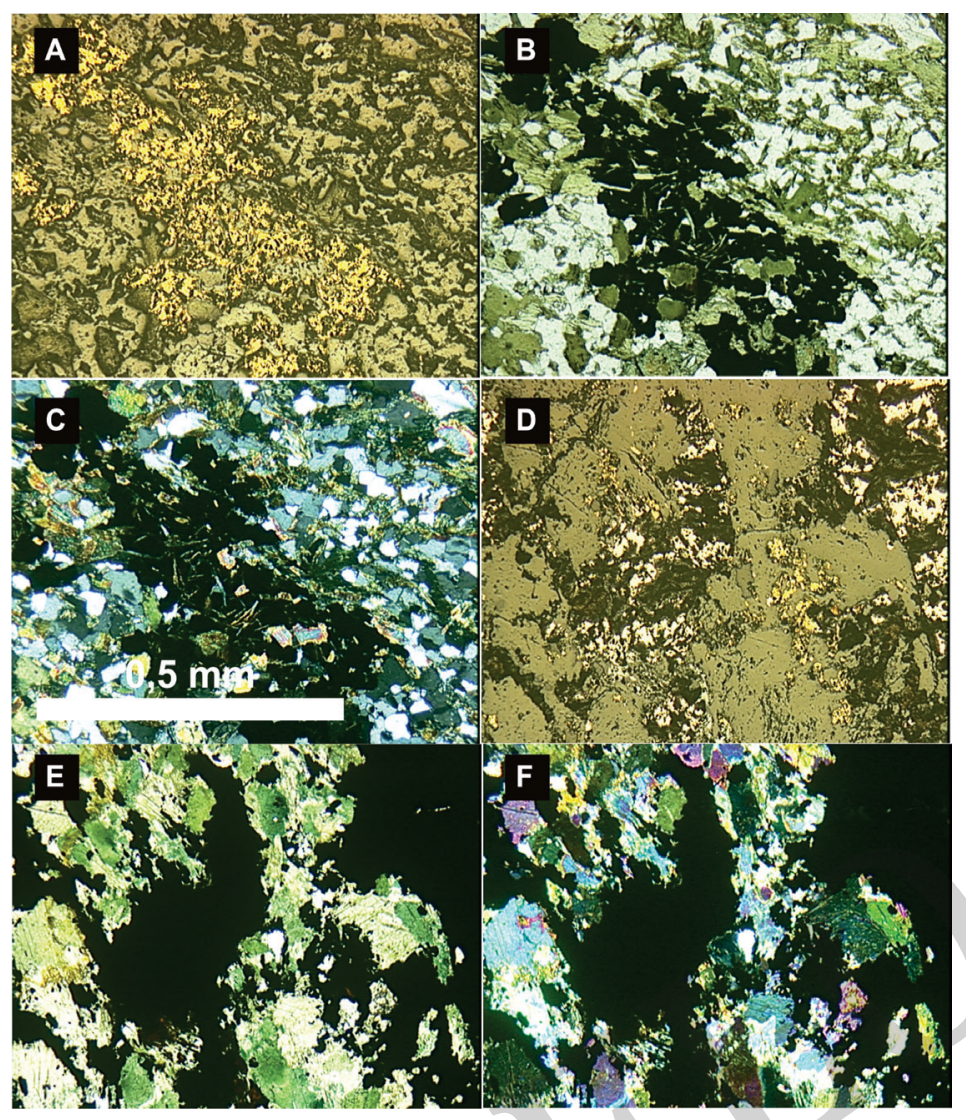

Figura 11. Fotomicrografias da rocha metavulcanossedimentar com forte alteração hidrotermal: (A, B e C) com agregados granoblásticos de quartzo, biotita e granada com substituição parcial por clorita, anfibólio e aglomerados xenoblásticos de calpirita e pirrotita, com ilmenita; (D, E e F) anfibólio e quartzo com pirrotita e calcopirita como disseminações e como agregados.

Os mesmos estão dispostos segundo direção NW-SE (Figura 5), com mergulhos tanto para SW (predominante) como para NE.

No Depósito Pojuca Corpo Quarto, a mineralização ocorre principalmente associada às rochas bandadas, e geralmente é concordante com as rochas encaixantes. A mineralização primária, nesse caso, é formada por calcopirita, pirrotita e esfalerita. Gahnita também pode ser encontrada em níveis mineralizados a Zn. Nas zonas remobilizadas, ocorre pirita, com pentlandita, molibdenita, covelita, bornita e Au. A mineralização do Depósito Pojuca Corpo Quatro, quando condicionado às rochas exalativas bandadas, tem geometria stratabound, podendo ocorrer também em string e em veios e vênulas de quartzo-biotita-turmalina. A mineralização mais típica tem bandas maciças milimétricas a centimétricas recorrentes de calcopirita e pirrotita, alternadas com bandas de quartzo e de anfibólio. De forma subordinada, a mineralização também pode ocorrer disseminada ou em vênulas e veios ou até mesmo na forma de grãos esqueletais seguindo a clivagem dos anfibólios. Não foi registrada uma correlação forte da mineralização sulfetada com o $\mathrm{Au}$, que é encontrado aleatoriamente, raramente excedendo $1,0 \mathrm{~g} / \mathrm{t}$. 0 s teores de $\mathrm{Ag}$ variam de $5 \mathrm{a} 10 \mathrm{~g} / \mathrm{t}$ e o Mo é encontrado na faixa de 30 a 70 ppm. Nos níveis mineralizados a $\mathrm{Zn}$ também podem ocorrer comumente altos valores de Cd, variando de 200 a 300 ppm. Tais dados, obtidos através de análises geoquímicas, resultaram da coleta de amostras de $1 \mathrm{~m}$, utilizando $1 / 4$ de testemunho, cujos elementos e métodos analíticos utilizados no Depósito Pojuca Corpo Quatro são explicitados no Quadro 1.

\begin{tabular}{|c|c|c|}
\hline Elementos & Unidade & Método \\
\hline$A_{1}$ & $\mathrm{~g} / \mathrm{t}$ & Fire Assay \\
\hline $\mathrm{Ag}$ & \multirow{3}{*}{ ppm } & \multirow{6}{*}{ Água Régia / Absorção Atômica } \\
\hline $\mathrm{Cd}$ & & \\
\hline $\mathrm{Zn}$ & & \\
\hline $\mathrm{Fe}$ & $\%$ & \\
\hline$M$ & ppm & \\
\hline \multirow{2}{*}{$\mathrm{Cu}$} & \multirow[t]{2}{*}{$\%$} & \\
\hline & & Água Régia / ICP-MS \\
\hline
\end{tabular}

Quadro 1. Elementos e métodos analíticos utilizados na pesquisa do Depósito Pojuca Corpo Quatro.

As discussões quanto às características dos fluidos responsáveis pela mineralização do Depósito Pojuca Corpo Quatro têm concluído que estes seriam de natureza sódico-cálcica, e que os metais carreados por estes fluidos estariam sob a forma de complexos clorídricos. Segundo estudos realizados pela VALE, o 
estágio inicial da mineralização (pirrotita-calcopirita \pm esfalerita) associa-se a fluidos aquosos ricos em Na-Ca-(K), de moderada salinidade, e o segundo estágio da mineralização esteve fortemente relacionado à formação de veios de quartzo-biotita, e foi gerada a baixa temperatura e alta salinidade, rica em fluidos $\mathrm{Na}-\mathrm{Ca}-\mathrm{K}$ -Fe (VALE, 2009).

Recentemente, foi proposto pela equipe de exploração mineral da VALE que a sequência clasto-química do Grupo Igarapé Pojuca (BIF, chert bandado e rocha fragmentada) seja revista em função da inexistência de rochas siliciclásticas no âmbito do depósito homônimo, particularmente no Corpo Quatro. A proposta é de que este pacote seja considerado como exalativo com intercalações de peperitos (rocha com fragmentos). Essas rochas apresentam uma polaridade quanto ao tamanho dos fragmentos, que aumentam em direção ao contato com os exalitos (rochas bandadas).

Um aspecto importante sobre o depósito, em especial suas relações genéticas referem-se às idades dos eventos. Neste sentido, uma fração de zircões $(9$ cristais) separados de anfibolito do Corpo Quatro fornece uma idade U-Pb concordante de $2732 \pm 2 \mathrm{Ma}$ (Machado et al., 1991). Essa idade é interpretada pelos autores como a idade de cristalização do anfibolito. O Granito Pojuca, que ocorre nas proximidades, fornece uma idade de $1874 \pm 2$ Ma baseada em uma discórdia de 3 frações de zircões (Machado et al., 1991).

Os metabasaltos encaixantes do depósito, a $\mathrm{N}$ e a $\mathrm{S}$, têm idade, geoquímica e origem semelhantes as das rochas do Grupo Grão Pará (Olszewski et al., 1989 e Machado et al., 1991). Nesse contexto, a melhor estimativa de idade para as rochas hospedeiras do Depósito Pojuca Corpo Quatro é a idade de 2,7 Ga da sequência de metabasaltos e gabros cogenéticos, que também hospedam o Depósito Gameleira adjacente. Neste último, Pimentel et al. (2002) obtiveram idades isocrônicas Sm-Nd de $2719 \pm 80$ Ma (MSWD=3.0) ( Nd(T) de -1.4) para metandesitos, que são parte das rochas encaixantes juntamente com os gabros. Quando plotados juntos, as rochas metavulcânicas e gabros associados indicam a idade de $2757 \pm 81 \mathrm{Ma}(1)$ ( $\mathrm{Nd}(\mathrm{T})$ de -0.8$)$. Essa idade é interpretada como representativa da época de cristalização das rochas vulcânicas encaixantes do depósito Gameleira. Os eventos diretamente ligados à mineralização do Depósito Pojuca Corpo Quatro ainda não estão devidamente datados, mas por correlação, sugere-se que as idades sejam similares.

0 modelo VMS proposto para o Depósito Pojuca Corpo Quatro ainda não tem boa aceitação pela comunidade, no entanto, uma série de características leva a crer em uma origem metalogenética primária vulcânica. Quando comparados dados geoquímicos de $\mathrm{Ce} \times \mathrm{Cu}$ de depósitos descritos e aceitos como IOCG, brechas e magnetititos maciços, também hospedados em rochas metavulcanossedimentares na mesma Província de Carajás, estes apresentam características muito distintas das de mineralizações stratabound (Fig. 12).

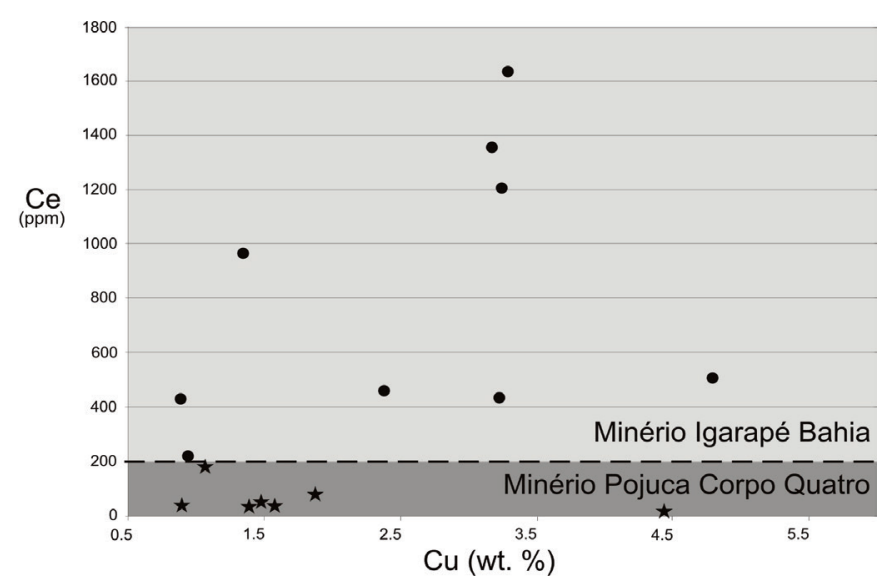

Figura 12. Gráfico comparativo de Ce x Cu para os depósitos de Igarapé Bahia (brechas e magnetititos) e Pojuca Corpo Quatro (stratabound). (modificado de CVRD, 2005, relatório interno).

Individualizando-se o Depósito Pojuca Corpo Quatro (com minério stratabound e minério remobilizado) dos depósitos adjacentes, outras características corroboram a ideia de que este tenha uma história metalogenética diferenciada dos demais depósitos cupríferos da Província Mineral de Carajás: (1) enquanto depósitos IOCG caracterizam-se por enriquecimento em elementos como Fe, K e Na, o Depósito Pojuca Corpo Quatro é empobrecido em álcalis (Na e K); (2) depósitos IOCG caracterizam-se por paragêneses de minerais de minério como calcopirita, bornita e calcocita, e também teores razoáveis de $\mathrm{Au}$, ao passo que em Pojuca Corpo Quatro a paragênese é dada por calcopirita, pirrotita e esfalerita, além de também possuir teores médios inferiores aos característicos dos depósitos do tipo ferro-óxido que em média têm teores de $\mathrm{Cu}$ de aproximadamente 1\%; (3) Pojuca Corpo Quatro é um depósito de $58 \mathrm{Mt}$, diferente dos padrões IOCG, geralmente maiores que $250 \mathrm{Mt}$; e, (4) o minério do Depósito Pojuca Corpo Quatro é bandado e disseminado em um corpo mineralizado de forma tabular com forte mergulho, enquanto em depósitos IOCG, via de regra, a mineralização ocorre disseminada em brechas e/ou magnetititos/hematititos de forma circular a lenticular.

As características e comparações citadas acima sugerem que o minério stratabound do Depósito Pojuca Corpo Quatro assemelhe-se a um depósito do tipo VMS, por sua paragênese primária, seu condicionamento stratabound, volume de minério, concordância com sequências vulcanogênicas e presença de alteração hidrotermal apenas na base do horizonte mineralizado. Já o minério secundário (remobilizado) foge do padrão VMS, distribuído de forma disseminada em anfibolitos, em brechas e vênulas de quartzo ou carbonato, contendo magnetita e ilmenita, que podem ser interpretados como parte de um sistema similar ao de um modelo genético do tipo ferro-óxido, considerando que estas características são comuns em depósitos do tipo IOCG.

A proximidade de outros dois depósitos bastante estudados a ESE, Gameleira e Grota Funda, pode explicar essas características identificadas para o miné- 
rio remobilizado. A presença de turmalina, mudança de paragênese e o enriquecimento em Fe de parte das rochas encaixantes remete ao Depósito Pojuca Corpo Quatro características que são presentes naqueles depósitos circunvizinhos.

A Província Mineral de Carajás é interpretada como tendo três principais eventos mineralizantes. 0 primeiro destes, associado ao vulcanismo do Grupo Grão Pará, é responsável pelos depósitos de Fe e Mn de Carajás e Azul, de idade aproximada de 2,7 Ga; depósitos tipo IOCG, gerados por um grande aporte de fluidos por volta de 2,5 Ga (depósitos de Sossego, Salobo, Igarapé Bahia, Grota Funda); e, finalmente, depósitos de remobilização precipitados em stockwork e correlacionáveis a intrusões de idade aproximada de 1,8 Ga, IOCG ou não, tendo como maior representante o Depósito Gameleira.

Levando-se em conta a proximidade geográfica e a possibilidade do encadeamento dos eventos mineralizantes descritos, e a correlação das rochas vulcânicas do Grupo Igarapé Pojuca com o vulcanismo do Grupo Grão Pará, de idade Arqueana, sugere-se que o minério primário (stratabound) desse depósito seja correlacionável aos episódios vulcanogênicos de idade 2,7 Ga.

Já as brechas, vênulas e disseminações de sulfetos características do minério remobilizado presentes no Depósito Pojuca Corpo Quatro, assim como as paragêneses com presença de (rara) molibdenita e turmalina, são sugestivas de resultarem de alterações hidrotermais similares às responsáveis pela gênese dos depósitos vizinhos de Gameleira e Grota Funda, mesmo que em posição mais distal.

Ao interpretar as grandes unidades rochosas da área do Depósito Pojuca Corpo Quatro, tomando como exemplo a seção vertical -300E, e correlacionando-as aos teores de um furo que corta todo este pacote de litologias nesta mesma seção (F38), é possível facilmente encaixar este depósito no modelo tipo VMS, como explicitado na figura 13, com efeitos de remobilização por eventos hidrotermais posteriores.

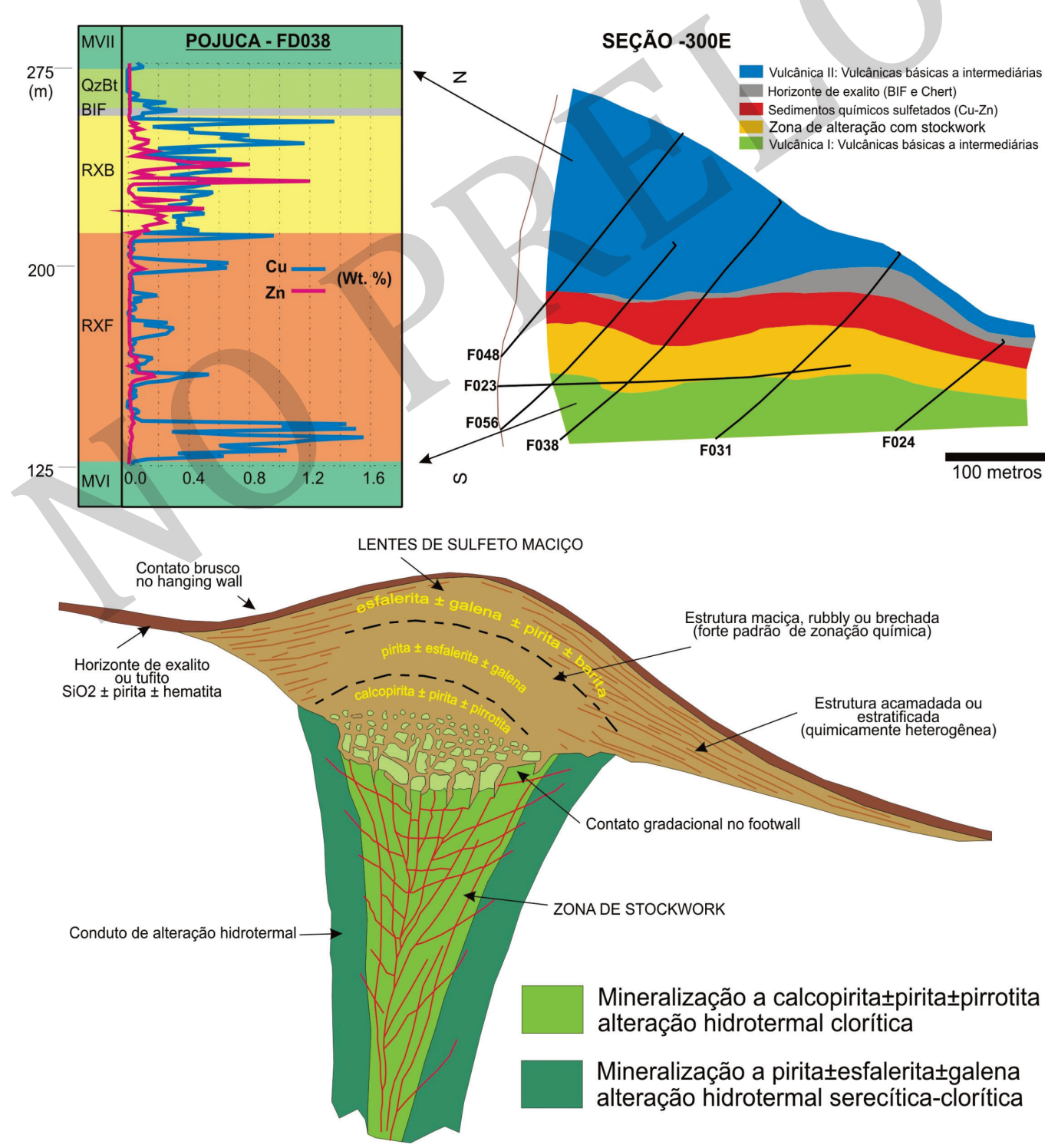

Figura 13. Esquema correlacionando tipos litológicos e teores da seção -300E do Depósito Pojuca Corpo Quatro com o modelo metalogenético do tipo VMS. 


\section{Conclusões}

O Depósito Pojuca Corpo Quatro, com suas reservas estimadas em 58 milhões de toneladas de minério, com teor médio de $0,87 \%$ de Cu e $0,90 \%$ de Zn, está hospedado em rochas que permitem uma correlação com as rochas do Grupo Grão Pará.

A paragênese do minério stratabound, suas características texturais e químicas, volume da mineralização e a forma do corpo de minério, permitem interpretar o depósito como sendo um depósito de origem e gênese vulcânicas, modelo VMS, de 2,7 Ga, conforme discutido nos parágrafos anteriores.

A paragênese do minério secundário, suas características texturais e químicas indicam contribuições e modificações geradas por eventos hidrotermais posteriores.

As características do minério secundário do Depósito Pojuca Corpo Quatro permitem estabelecer uma correlação com o minério dos depósitos Grota Funda e Gameleira, ambos definidos como do tipo IOCG, conforme sua associação com zonas brechadas que acompanham intrusões e suas paragêneses compatíveis com sistemas intrusivos oxidados.

Os depósitos IOCG deste distrito têm idades sugeridas de 2,5 e de 1,8 Ga, sendo que estas idades são sugestivas para representarem os efeitos de remobilização observados no Depósito Pojuca Corpo Quatro.

0 entendimento da complexidade dos processos envolvidos na gênese do Depósito Pojuca Corpo Quatro demanda estudos mais aprofundados para aperfeiçoamento do modelo do depósito, em especial de técnicas que envolvam datação direta de zonas de alteração hidrotermal e de minério e de suas paragêneses. Sugere-se que seja utilizado o método Re-Os para sulfetos, datando pirita e calcopirita do minério stratabound e calcopirita e molibdenita presente em vênulas de minério remobilizado.

Agradecimentos - Os autores agradecem a VALE pela oportunidade de realizar o presente estudo em uma de suas áreas de exploração mineral, aos gerentes de exploração pela liberação do artigo para publicação, ao editor-chefe da revista e aos revisores pela acurada análise do trabalho, oportunas críticas e importantes contribuições.

\section{Referências}

Althoff, F.J., Barbey, P. \& Boullier, A.M. 2000. 2.8-3.0 Ga plutonism and deformation in the SE Amazonian craton: the Archean granitoids of Marajoara (Carajás Mineral province, Brazil). Precambrian Research, 104:187-206.

Araújo, O.J.B. \& and Maia, R.G.N. 1991. Projeto especial mapas de recursos minerais, de solos e de vegetação para a área do Programa Grande Carajás; Subprojeto Recursos Minerais; Folha SB.22-Z-A Serra dos Carajás - Estado do Pará. Brasilia, DNPM/CPRM, 136p.

Araújo, O.J.B., Maia, R.G.N., Jorge João, X. S., \& Costa, J.B.S.
1988. A megaestruturação arqueana da Folha Serra dos Carajás. In: CONGRESSO LATINO AMERICANO DE GEOLOGIA, 1., 1988, Belém. Anais... Belém, v.1, p.324-338.

Barbosa, J.P.O, Barros, C.E.M., Macambira; M.B. \& VALE, A.G. 2001. Geologia e Geocronologia do Stock Granítico Geladinho, região de Parauapebas, Província Mineral de Carajás. In: SIMPÓSIO DE GEOLOGIA DA AMAZÔNIA, 7.,2001, Belém. CD-ROM, Resumos Expandidos. Belém: SBG-NO, 2001. v. 7. p. 12-15.,

Barbosa, O., Ramos, J.R. de A., Gomes, F. de A. \& Helmbold, R. 1966. Geologia estratigráfica, estrutural e econômica da área do "Projeto Araguaia". DGM, Rio de Janeiro, 94p.

Barros, C.E.M. 1997. Pétrologie et struture du Complexe Granitique Estrela (2.5 Ga) et de son encaissant métavolcano-sédimentaire (Province Métallifère de Carajás, Brésil). Nancy, 316p. Tese de Doutorado, Université Henri Poincaré, França.

Barros, C.E.M., Dall'agnol, R., Vieira, E.A.P. \& Magalhães, M.S. 1995. Granito Serra dos Carajás: avaliação do potencial metalogenético para estanho com base em estudos da borda oeste do corpo. Série Ciências da Terra, 7: 93-123.

Barros, C.E. M. 1991. Evolução petrológica e estrutural do Gnaisse Estrela, Curionópolis, PA. Belém, 134p. Dissertação de Mestrado, Curso de Pós-Graduação em Geociências, Universidade Federal do Pará.

Barros, C.E. M., Dall'agnol, R., Soares, A.D.V. \& Dias, G.S. 1994. Metagabros de Águas Claras, Serra dos Carajás: Petrografia, Geoquímica e transformações metamórfico-hidrotermais. Acta Geologica Leopoldensia, 17(40): 31-70.

Barros, C.E.M. \& Barbey, P. 1998. A importância da granitogênese tardi-arqueana (2,5 Ga.) na evolução tectono-metamórifca da província mineral de Carajás - 0 Complexo Granítico Estrela e sua auréola de contato. Revista Brasileira de Geociências. 28(4): 513-522.

Barros, C.E.M., Macambira, M.J.B. \& Barbey, P. 2001. Idade de zircão do Complexo Granítico Estrela: relações entre magmatismo, deformação e metamorfismo na Província Mineral de Carajás. In: SIMPÓSIO DE GEOLOGIA DA AMAZÔNIA, 7., 2001, Belém, Anais... Belém, SBG. 1 CD-ROM.

Beisiegel, V. de R., Bernardelli, A.L., Drummond, N.F., RUFF, A.W. \& Tremaine, J.W. 1973. Geologia e recursos minerais da Serra dos Carajás. Revista Brasileira de Geociências, 3 : 215-242.

Brodie, K., Fettes, D., Harte, B. \& Schmid, R. 2004. Towards a unified nomeclature of metamorphic petrology. Structural terms including fault rock terms. Recommendations by the IUGS Subcommission on the Systematics of Metamorphic Rocks. IWeb version.

Caputo, M.V. \& Lima, E.C. 1984. Estratigrafia, idade e correlação do Grupo Serra Grande - Bacia do Parnaíba. In: CONGRESSO BRASILEIRO DE GEOLOGIA, 33., 1984, Rio de Janeiro. Anais...Rio de Janeiro, SBG, v.8, p. 740-753.

Costa J.B.S., Araújo, O.J.B., Santos, A., Jorge João, X.S., MacaMBIRA, M.J.B. \& Lafon, J.M. 1995. A Província Mineral de Carajás: aspectos tectono estruturais, estratigráficos e geocronológicos. Série Ciências da Terra, 7: 199-235.

Costa, J.B.S. \& Hasuí. 1996. Evolução geológica da Amazônia. In Costa, M. L. \& Angélica (Eds). Contribuições à geologia da Amazônia. 15-90 p.

Costa, J.B.S., Hasui, Y., Bemerguy, R.L., Borges, M. da S., Costa, A.R., Travassos, W., Mioto, J.A. \& Igreja, H.L.S. 1993. Aspectos fundamentais da neotectônica na Amazônia Brasileira. In: SIMPÓSIO INTERNACIONAL DO QUATERNÁRIO DA AMAZÔNIA, 1993, Manaus. Resumos e Contribuições 
Científicas... Manaus, p. 103-106.

Couto, D., Fonseca, E., Alves, V.K., Gonçalves, K.L., Araújo, I. \& Kwitko, R. 2006. Avaliação do comportamento tecnológico do minério de cobre sulfetado de Furnas, Carajás. - estudo exploratório. 31p.

DOCEGEO. Rio Doce Geologia e Mineração S.A. 1988. Revisão litoestratigráfica da Província Mineral de Carajás. In: CONGRESSO BRASILEIRO DE GEOLOGIA, 35., 1988, Belém. Anais... Belém, SBG, v.1, p. 10-54.

Galarza, T.M.A. 2002. Geocronologia e geoquímica isotópica dos depósitos de Cu-Au Igarapé Bahia e Gameleira, Província Mineral de Carajás (PA), Brasil. Belém, 214p. Tese de Doutorado, Centro de Geociências, Universidade Federal do Pará.

Gibbs, A.K., Wirth, K.R., Hirata, W.K. \& Olszewski Jr., W.J. 1986. Age and composition of the Grão Pará Group volcanics, Serra dos Carajás. Revista Brasileira de Geociências, 16(2), 201-211.

Hirata, W.K., Rigon, J.C., Cordeiro, A.A.C. \& Meireles, E. M. 1982. Geologia regional da Província Mineral de Carajás. In: SIMPÓSIO DE GEOLOGIA DA AMAZÔNIA, 1., 1982, Belém. Anais... Belém, SBG, v.1, p.100-108.

Leite, A.A.S. 2001. Geoquímica, petrogênese e evolução estrutural dos granitóides arqueanos da região de Xinguara, SE do Cráton Amazônico. Belém, 330p. Tese de Doutorado, Centro de Geociências, Universidade Federal do Pará.

Lindenmayer, Z. 2003. Geologia do Depósito de $\mathrm{Cu}-\mathrm{Au}$ de Gameleira, Serra dos Carajás, Pará. In: Caracterização dos depósitos auríferos em Distritos minerais brasileiros. ADIMB, p. 81-139.

Lindenmayer, Z.G. \& Fyfe, W.S. 1991 - Metamorfismo de alta temperatura e baixa pressão no depósito de cobre do Salobo: evidência do rift continental arqueano no Cráton Amazônico. In: SIMPÓSIO DE GEOLOGIA DA AMAZÔNIA, 3., 1991, Belém. Anais... Belém, SGB, v.1, p. 36-48.

Lindenmayer, Z.G. 1990. Salobo Sequence, Carajás, Brasil: geology, geochemistry and metamorphism, London, 407p. Tese de Doutorado, University of Western Ontario, Canadá.

Lindenmayer, Z.G. \& Teixeira, J.B.G. 1999. Ore Genesis at the Salobo Copper Deposit, Serra dos Carajás. In: Silva, M.G \& Misi, A. (eds.). Base Metal Deposits of Brazil. Belo Horizonte, MME/CPRM/DNPM, p. 33-43.

Lindenmayer, Z.G., Fyfe, W.S. \& Bocalon, V.L.S. 1994. Nota preliminar sobre as intrusões granitóides do depósito de cobre do Salobo, Carajás. Acta Geológica Leopoldensia, 17 (40): 153-184.

Lindenmayer, Z.G., Pimentel, M.M., Althoff, F.J. \& Teixeira, J.B.G., 2001 - Hidrotermalitos: nova denominação para as formações ferríferas do Grupo Salobo-Pojuca, Serra dos Carajás, Pará. In: SIMPÓSIO DE GEOLOGIA DA AMAZÔNIA, 7., 2001, Belém. Anais... Belém, SBG, CD-ROM.

Macambira, M.J.B. \& Lafon, J.M. 1995. Geocronologia da Província Mineral de Carajás; Síntese dos dados e novos desafios. Série Ciências da Terra, 7: 263-288.

Macambira, M.J.B., Lima, L.M., Pinheiro, R.V.L. \& Lima, F.D. 2001. Idades de Cristais Detríticos de Zircão da Serra dos Carajás, Pará; Evidências sobre a Formação da Crosta. In: VII SIMPÓSIO DE GEOLOGIA DA AMAZONIA, 7., 2001, Belém. Anais... Belém, SBG, CD-ROM.

Machado, W., Lindenmayer, Z.G., Krogh, T.E. \& Lindenmayer, D. 1991. U-Pb geochronology of Archean magmatism and basement reactivation in the Carajás área, Amazon shield, Brazil. Precambrian Research, 49: 329-354.

Matos, F.M.V., Paim, M.M. \& Ferreira Filho, C.F. 2005. O Depó- sito de Pojuca - Corpo 4. CVRD, (Companhia Vale do Rio Doce), Poster. (Apresentação interna).

Mikucki, E.J. \& Ridley, J.R. 1993. The hydrothermal fluid of Archean lode-gold deposits atdifferent metamorphic grades: compositional constraints from ore and wallrock alteration assemblages. Mineralium Deposita, 28(6): 469481.

Mougeot, R., Respaut, J.P., Brique, L., Lédru, P., Milesi, J.P., Lerouge, C., Maroux, E., Huhn, S.B. \& Macambira, M.J.M. 1996. Isotope geochemsitry constrains for $\mathrm{Cu}, \mathrm{Au}$ mineralizations and evolution of the Carajás Province (Para, Brazil). In: CONGRESSO BRASILEIRO DE GEOLOGIA, 39., 1996, Salvador. Anais... Salvador, SBG, v. 7, p.321-324.

Nogueira, A.C.R., 1995. Análise faciológica e aspectos estruturais da Formação Águas Claras, Região Central da Serra dos Carajás - Pará. Belém, 167p. Tese de Doutorado, Curso de Pós-Graduação em Geociências, Universidade Federal do Pará,

Nogueira, A.C.R., Truckenbrodt, W. \& Pinheiro, R.V.L. 1996. Formação Águas Claras, Pré-Cambriano da Serra dos Carajás. Redescrição e redefinição. Série Ciências da Terra, 7:177-197.

Olszewski, W.J, Wirth, K.R., Gibbs, A.K. \& Gaudette, H.E. 1989. The age, origin, and tectonics of the Grão Pará Group and associated rocks, Serra dos Carajás, Brazil: Archean continental volcanism and rifting. Precambrian Research, 42: 229-254.

Pidgeon, R.T., Macambira, M.J.B. \& Lafon, J.M. 2000. Th-U-Pb isotopic systems and internal structures of complex zircons from na enderbite from the Pium Complex, Carajás Province, Brazil: evidence for the ages of granulite facies metamorphism and the protolith of the enderbite. Chemical Geology, 166: 159- 171.

Pimentel, M.M.; Lindenmayer, Z.G.; Laux, J.H.; Armstrong, R.; Araújo, J.C., 2002 - Geochronology and Nd isotope geochemistry of the Gameleira $\mathrm{Cu}-\mathrm{Au}$ deposit, Serra dos Carajás, Brazil: 1,8-1,7 Ga hydrothermal alteration and mineralization. Journal of South American Earth Sciences, 15: 803-813.

Pinheiro, R.V.L. \& Holdsworth, R.E. 1995 - Significado tectônico da clivagem transversa (transecting cleavage) em dobras na Mina de Serra Pelada, Pará. Série Ciências da Terra, 7: 259-278.

Pinheiro, R.V.L. \& Holdsworth, R.E. 2000. Evolução Tectonoestratigráfica dos Sistemas Transcorrentes Carajás e Cinzento, Cinturão Itacaiúnas, na borda leste do Cráton Amazônico, Pará. Revista Brasileira de Geociências, 30 (4): 597-606.

Pinheiro, R.V.L. 1997. Reactivation history of the Carajás and Cinzento Strike-Slip System, Amazon, Brazil. Durham, 408p. Tese de Doutorado, University of Durham.

Ramos, J.R. 1967. Estratigrafia da região do Xingu-Tocantins. In: SIMPÓSIO SOBRE A BIOTA AMAZÔNICA, 1966, Belém. Atas... Rio de Janeiro, CNPq, v.1, p.373-388.

Ridlye, J. 2005. Orogenic (Mesothermal) gold Deposits: Constraining Patterns of Ore Fluid Flow and Chemical Controls on Ore Depositon. Society Geologists' Denver Region Exploration (Aprentação Técnica).

Rodrigues, E.S.; Lafon, J.M. \& Scheller, T. 1992 - Geocronologia $\mathrm{Pb}-\mathrm{Pb}$ da Província Mineral de Carajás: primeiros resultados. In: CONGRESSO BRASILEIRO DE GEOLOGIA, 37., 1992, São Paulo. Boletim de Resumos Expandidos... São Paulo, v.2, p. 183-184.

Santos, B.A, 1981 - Geologia e Potencial Mineral da Região de 
Carajás. DOCEGEO, 46 p. (Relatório Interno).

Santos, N., Fonseca, E. \& Tallarico, J. 2003. Avaliação do estilo de mineralização e comportamento tecnológico do minério de Furnas, Carajás. CVRD, 53p. (Relatório Interno).

Sardinha, A.S., Barros, C.E.M., Krymski, R. \& Macambira, M.J.B. 2001. Petrografia e Geocronologia U-Pb em zircão do Granito Serra do Rabo, Província Mineral de Carajás, Pará. In: SIMPÓSIO DE GEOLOGIA DA AMAZONIA, 7., 2001, Belém. Anais... SBG, CDROM.

Sibson, R.H., 1977. Fault rocks of the Moine Thrust Zone. Texture and microestructures. Journal of the Geological Society, 133:191-213.

Sibson, R.H. 1990. Faulting and fluid flow. In: B.E. Nesbitt (ed.) Fluids in Technically Active Regimes of the Continental Crust. Nepean, Mineral Association Canada, p.92132

Silva, G.G., Lima, M.J.C., Andrade, A.R.F., Issler, R.S. \& Guimarães, G. Geologia das folhas SB-22 Araguaia e parte SC-22 Tocantins, Projeto RADAMBRASIL, geologia, geomorfologia, solos e uso potencial da terra, Levantamento de Recursos Naturais. Rio de Janeiro, 143p.

Skinner, B.J. \& Barton, P.B. 1973. Genesis of Mineral Deposits. Annual Review of Earth Planetary Science Letters, 1: 183211.

Skirrow, R. 2004. Iron oxide $\mathrm{Cu}-\mathrm{Au}$ deposits: An Australian perspective on their unifying characteristics. In: McPhie, J. and McGoldrick, P. (eds), 2004. Dynamic Earth: Past, Present and Future. Tasmania, Geological Society of Australia, p.121.

Soares, A.V., Santos, A.B., Vieira, E.A., Bella, V.M. \& Martins, L.P.B. 1994. Área Águas Claras contexto geológico e mineralizações. In: IV SIMPÓSIO DE GEOLOGIA DA AMAZÔNIA, Belém, 1994. Boletim de Resumos Expandidos.. p.379-382.

Souza, S.R.B., Macambira, M.J.B. \& Sheller, T. 1996. Novos dados geocronológicos para os granitos deformados do Rio Itacaiúnas (Serra dos Carajás, PA); implicações estratigráficas. In: SIMPÓSIO DE GEOLOGIA DA AMAZONIA, 5.,
Belém, 1996. Anais... Belém, SBG, p.380-383.

Tassinari, C.C.B. \& Macambira, M.J.B. 1999. Geochronological provinces of the Amazonian Craton. Episodes, 22 (03), 174-182.

Teixeira, J.B.G. \& EgglER, D.H. 1994. Petrology, Geochemistry, and Tectonic Setting of Archaean Basaltic and Dioritic Rocks from the N4 Iron Deposit, Serra dos Carajás, Pará, Brazil. Acta Geologica Leopoldensia, 17: 71-114.

Teixeira, W., Tassinari, C.C.G., Cordani, U.G. \& Kawashita, K. 1989. A review of the geochronology of the Amazonian Craton: tectonic implications. Precambrian Research, 42:213- 227.

Trendall, A.F., Basei, M.A.S., Laeter, J.R. \& Nelson, D.R., 1998 SHRIMP zircon U-Pb constraints on the age of the Carajás formation, Grão Pará Group, Amazon Craton. Journal of South American Earth Sciences, 11 (3) 65-277.

VALE S.A. 2009. Revisão na tipologia de minério do Depósito Pólo, 99p. (Relatório interno).

Villas, R.N. \& Santos, M.D. 2001. Gold deposits of the Carajás mineral province: deposit type and metallogenesis. Mineralium Deposita, 36: 300-331.

Villas, R.N. \& Galarza, M.A. 2001 - As Brechas Hidrotermais do Depósito Igarapé Bahia, Carajás: Dados Geoquímicos e de Isótopos Estáveis de Carbono e Enxofre. In: VII SIMPÓSIO DE GEOLOGIA DA AMAZONIA, 7., 2001, Belém. Anais... Belém, SBG, CD-ROM.

Walshe, J.L. \& Solomon, M. 1981. An investigation into the environment of formation of the volcanic hosted Mt. Lyell copper deposits using geology, mineralogy, stable isotopes, and a six-component chlorite solid solution model. Economic Geology, 76: 246-284.

Winter, C.J. 1994. Geology and base-metal mineralization associated with Archaean Iron Formation in the Pojuca Corpo Quatro Deposit, Carajás, Brazil. Southamptom, 244p. Tese de Doutorado, University of Southampton, Reino Unido.

\section{Manuscrito 496}

Editor: Paulo A. Souza. 


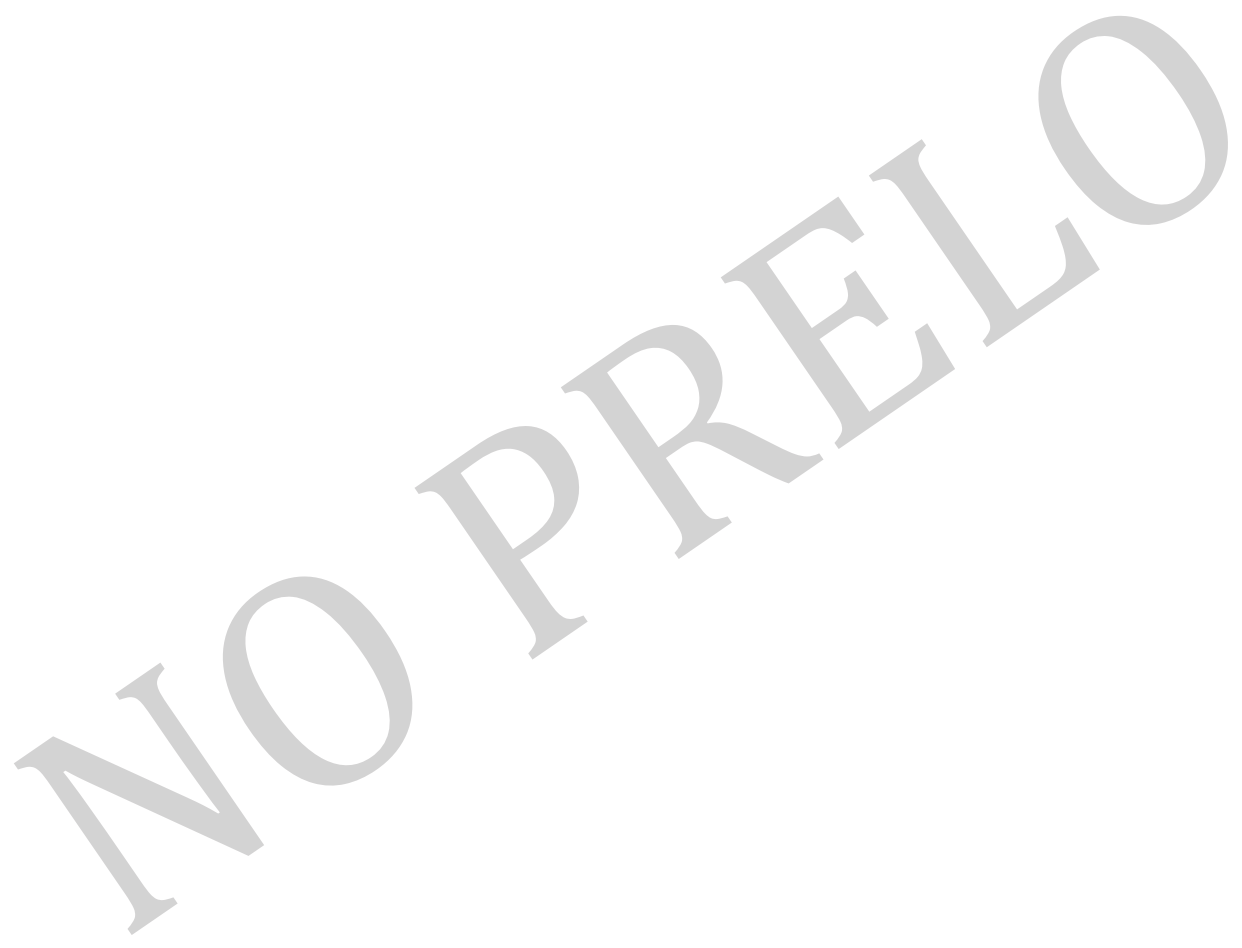

